\title{
Androgens and masculinization of genitalia in the spotted hyaena (Crocuta crocuta). 1. Urogenital morphology and placental androgen production during fetal life
}

\author{
P. Licht ${ }^{1}$, T. Hayes ${ }^{1}$, P. Tsai ${ }^{1}$, G. Cunha ${ }^{2}$, H. Kim ${ }^{2}$, M. Golbus ${ }^{2}$, \\ S. Hayward ${ }^{2}$, M. C. Martin', R. B. Jaffe ${ }^{2}$ and S. E. Glickman ${ }^{3}$ \\ ${ }^{1}$ Department of Integrative Biology, University of California at Berkeley, Berkeley, CA 94720; ${ }^{2}$ Reproductive \\ Endocrinology Center, Department of Obstetrics, Gynecology, University of California, San Francisco, \\ San Francisco, CA 94143; and ${ }^{3}$ Department of Psychology, University of California at Berkeley, Berkeley, \\ CA 94720, USA
}

\begin{abstract}
According to common understanding of sexual differentiation, the formation and development of a penile clitoris in female spotted hyaenas requires the presence of naturally circulating androgens during fetal life. The purpose of the present study was to determine potential source(s) of such fetal androgens by investigating the timing of urogenital development and placental production of androgen during early and mid-gestation. Fetuses determined to be female by molecular techniques (lack of SRY gene) at days 33 and 48 of gestation had undifferentiated gonads, but the clitoris was already 'masculinized' and was generally similar to the phallus of a 50-day-old male fetus. Wolffian and Müllerian ducts terminated at the urogenital sinus in both sexes and a urethra was present along the entire length of the clitoris and penis. The adrenal gland was large and histologically differentiated at 33 days. Steroid gradients across the uterus (a drop in $\Delta^{4}$-androstenedione, with increases in oestrogen and androgen), and high androstenedione in ovarian veins indicated that ovarian androstenedione was metabolized and secreted as testosterone by the placenta throughout gestation. In vitro, whole or homogenized placentae at days 48 and 58 of gestation ( 110 days total) metabolized radiolabelled androstenedione into testosterone and oestradiol; the specific enzymatic activity of early placental tissues was higher than at later stages. A human placental homogenate had higher aromatase activity but did not produce testosterone unless aromatase was inhibited. Infusion of labelled androstenedione into the uterine arteries of hyaenas demonstrated the conversion of this substrate into testosterone and oestradiol and their secretion into the fetal circulation. Evidently, androgen is produced by the placenta and secreted into the fetal circulation from early in pregnancy when masculinization is first evident, before differentiation of the fetal ovary.
\end{abstract}

\section{Introduction}

Female spotted hyaenas (Crocuta crocuta) present an extreme case of natural female pseudohermaphroditism. The external labia of the vagina fuse to form a pseudoscrotum and the clitoris develops into an erectile pseudophallus through which the urethra and vagina open (Watson, 1877; Matthews, 1939; Neaves $e t$ al., 1980). The female also tends to be heavier, more aggressive and behaviourally dominant over males (Kruuk, 1972; Frank, 1986). Current understanding of sexual differentiation relies on the secretion of testosterone by the fetal testes to explain development of the penis from the genital tubercle, and fusion of the external labia of the vagina to form the scrotum (Jost et al., 1973; Wilson et al., 1981, 1983). There is no other explanation in the literature to account for formation of

Received 17 August 1997. a penis-like structure in mammals. Consequently, a search for fetal androgens in female spotted hyaenas has marked recent attempts to account for their unusually 'masculinized' external genitalia. In addition, exogenous testosterone, supplied during critical periods in fetal or neonatal life has been shown to increase the aggressiveness of female mammals (Goy and Resko, 1972; Monaghan and Glickman, 1992). Such androgens may also have modified the brain of fetal hyaenas, facilitating female aggression during adult life and promoting the exceptional neonatal aggression observed in these animals (Frank ef al., 1991).

Two proposals have been advanced to account for the circulation of androgens in female hyaenas during fetal life. Matthews (1939) proposed that the fetal ovary might be the source of androgen because his histological studies revealed a deficiency of follicular tissue and an abundance of steroidogenic tissue. Racey and Skinner (1979) also suggested that the fetal 
ovary was the site of androgen production after demonstration of high concentrations of androgens in female fetuses from pregnant females that were killed in the course of culling operations. More recently, our studies of captive pregnant hyaenas have indicated that the placenta rather than fetal ovaries is a likely source of testosterone and, in particular, that placental production of testosterone is derived from relatively high concentrations of $\Delta^{4}$-androstenedione (androst-4-ene3,17 ,dione) produced by the maternal ovary (Glickman et al., 1992; Licht $e$ al., 1992; Yalcinkaya $e t$ al., 1993); the abundance of ovarian steroidogenic tissue noted by Matthews (1939) may be important from this standpoint.

However, all our published data have been derived from hyaenas near term, between days 85 and 100 of a 110 day gestation (Licht et al., 1992; Yalcinkaya et al., 1993). By this time, the fetus is well developed and genital masculinization is complete. Thus, these data alone do not allow the conclusion that high placental testosterone formation is responsible for the formation of a pseudoscrotum and a penile clitoris. In addition, the results of Goy et al. (1988) in rhesus monkeys suggest that, in species with a long gestation, androgenic organization of the neural system involved in mediating sexual behaviour occurs at an early stage of gestation, while the system mediating vigorous social play is organized independently and later in gestation. Therefore, it is essential to know whether the placental conversion of androstenedione to testosterone observed in late gestation is present and available to the developing fetal brain throughout gestation, that is, during the periods when the neural systems underlying the social repertoire of the hyaena are developing.

The purpose of the present study was to gather additional information on the timing of genital development and associated steroid patterns during early stages of differentiation to increase understanding of the hormonal basis of masculinization in hyaenas. If, as Lindeque and Skinner (1982) suggest, the fetal ovary is a primary source of the androgens underlying the masculinization of the clitoris, then histological differentiation of the fetal ovary should precede the appearance of a genital tubercle traversed by a central urogenital canal. Alternatively, if placental testosterone underlies the masculinization of the clitoris, then the metabolic conversion of maternal androstenedione to testosterone should occur during the stages of pregnancy when the penile clitoris is formed. These hypotheses were tested by examining the anatomical development of the fetal urogenital system and correlating the results with studies of placental metabolism. These latter experiments involved the measurement of plasma steroid profiles across the placenta in vivo and observations of placental metabolism in vitro in timed pregnancies interrupted with Caesarean sections. The distribution and metabolism of radiolabelled androstenedione infused into the uterine artery were also examined to determine whether this steroid serves as the source of testosterone in the fetus.

\section{Methods}

\section{Animals and surgical procedures}

The data presented in this paper were derived from seven Caesarian sections, performed on pregnant female hyaenas in the Berkeley colony. Hyaenas were immobilized with intramuscular injections of ketamine $\left(4-6 \mathrm{mg} \mathrm{kg}^{-1}\right)$ and xylazine (1 mg kg ${ }^{-1}$ ), delivered via blowdarts. Sterile surgical procedures were then performed by University of California Veterinary staff after the subjects were intubated and maintained under inhalation anaesthesia (isoflourene). All procedures were approved by the Animal Care and Use Committee of the University of California at Berkeley (Protocol R091-0397R).

\section{Estimates of gestational age}

Mating and fertilization are not as predictable in hyaenas as in common domesticated animals. Individual, sexually experienced, female hyaenas were paired with familiar, sexually experienced males for various periods to ensure that fertilization took place. This period established the 'boundaries' within which fertilization might have occurred. In general, it was assumed that the midpoint of the interval during which a particular pair was housed together represented the best estimate of fertilization. However, we also calculated gestational age from the fetal growth equation developed by Huggett and Widdas (1951) as elaborated by Frazer and Huggett (1974). This equation permits estimation of fetal age from fetal mass with reasonable accuracy during the latter two thirds of gestation, but not the earliest stages of gestation. Lindeque and Skinner (1982) used this equation to estimate the ages of fetal hyaenas obtained in the field. The estimated duration of gestation ( 110 days) and species constant $(a=0.13)$ recommended by Frazer and Huggett (1974) and the intercept (22 days) used by Lindeque and Skinner were used in the present study. The boundaries for fertilization, midpoints within these boundaries and mathematically estimated fetal ages are all presented, together with information regarding fetal sex, fetal mass at cross-section, and anatomical-endocrine procedures performed in association with each cross-section (Table 1). During mid- and late-gestation, there is reasonable agreement between the midpoint estimates for fetal age, based on the time of pairing females and males, and the mathematical estimates based on a standard growth equation. However, as might be expected from an equation in which a 22 day fetus is projected to have a mass of $0 \mathrm{~g}$, the mathematical estimates derived from early fetal masses underestimate true fetal age. This is most clear in our earliest Caesarian section (pregnancy A), in which the growth equation predicts that fertilization occurred I day before the female and male hyaenas were actually paired. For pregnancies $B-E$, it is possible that conception occurred at a slightly later time than the midpoint of the period in which animals were housed together, resulting in overestimates of the age of each fetus. However, in designating fetal age throughout this paper, the midpoint estimate has been used as this is the statistical value that minimizes potential error in either direction. Ultimately, the logical implications of the data would be the same, whether, for example, a $12 \mathrm{~g}$ fetus was derived from day 40 (as predicted by the growth equation) or day 48 of gestation, the midpoint of the period when the animals were housed together. It should also be noted that, when comparing urogenital development in $12 \mathrm{~g}$ female fetuses (pregnancy B) with the $16 \mathrm{~g}$ male fetus (pregnancy $\mathrm{C}$ ), 
Table 1. Summary of experimental animals and procedures

\begin{tabular}{|c|c|c|c|c|c|}
\hline \multirow[b]{2}{*}{ Pregnancy } & \multicolumn{2}{|c|}{ Gestational age (days) } & \multicolumn{2}{|c|}{ Fetal conditions } & \multirow[b]{2}{*}{ Procedure } \\
\hline & Boundaries & Estimate* & Sex & Mass $(\mathrm{g})$ & \\
\hline A & $31-36$ & $33 \quad(30)$ & Female** & 1.1 & $\begin{array}{l}\text { Steroid gradients } \\
\text { Anatomy }\end{array}$ \\
\hline B & $44-52$ & $48 \quad(40)$ & $\begin{array}{l}\text { Female** } \\
\text { Female** }\end{array}$ & $\begin{array}{l}12 \\
12\end{array}$ & $\begin{array}{l}\Delta^{4} \mathrm{~A} \text { infusion }{ }^{\dagger} \\
\text { Placental metabolism } \\
\text { Steroid gradients } \\
\text { Anatomy }\end{array}$ \\
\hline C & $41-58$ & $50 \quad(41)$ & Male & 16 & $\begin{array}{l}\text { Steroid gradient } \\
\text { Anatomy }\end{array}$ \\
\hline $\mathrm{D}$ & $50-65$ & $58 \quad(50)$ & $\begin{array}{l}\text { Male } \\
\text { Male }\end{array}$ & $\begin{array}{l}46 \\
53\end{array}$ & $\begin{array}{l}\Delta^{4} A \text { infusion } \\
\text { Placental metabolism }\end{array}$ \\
\hline$E$ & $50-75$ & $64 \quad(58)$ & Male & 100 & \\
\hline $\mathrm{F}$ & $71-85$ & $78 \quad(81)$ & Male & 453 & $\begin{array}{l}\Delta^{4} \mathrm{~A} \text { infusion }{ }^{\dagger} \\
\text { Placental metabolism } \\
\text { Steroid gradients }\end{array}$ \\
\hline G & - & $-(103)$ & $\begin{array}{l}\text { Female } \\
\text { Male }\end{array}$ & $\begin{array}{l}1100 \\
1120\end{array}$ & $\begin{array}{l}\Delta^{4} A \text { infusion }{ }^{\dagger} \\
\text { Steroid gradients }\end{array}$ \\
\hline
\end{tabular}

*First value based on mid-point of time together, value in parenthesis is based on calculation from equation of Frazer and Huggett (1974).

**Based on polymerase chain reaction.

$\Delta^{4} \mathrm{~A}, \Delta^{4}$ androstenedione; ${ }^{\dagger}$ radiolabelled androstenedione.

the midpoint estimates suggest a 2 day difference in fetal age, while the mathematical equation predicts a 1 day difference in fetal age. Both methods indicate that these fetuses are very close in age.

\section{Morphological methods and determination of sex}

Anatomical studies. All fetuses used in this study were photographed after delivery, and morphometric measurements were taken. A description of external features was also made. After thorough external examination, the abdominal cavity was opened and fragments of liver together with amniotic fluid were taken for subsequent extraction of DNA for determination of sex of fetuses that were still in the ambisexual stage. The gastrointestinal tract was removed to allow inspection and photography of the urogenital tract on the posterior abdominal wall. The gonads and urogenital ridge were freed of their mesenteric attachments to the posterior abdominal wall, and the entire urogenital tract was removed and carefully dissected from the gonads to the genital tubercle. The isolated genital tract was photographed both with reflected light and with transmitted light projected through the specimen. The latter method allows the examination of internal epithelial structures such as the Wolffian and Müllerian ducts. After photographic documentation, the urogenital tract was blocked into segments for histological examination. For histology, specimens were fixed in buffered formalin. For one specimen, the patency of the urethra was determined by injecting India ink into the urinary bladder with a syringe after ligation of the ureters.

Determination of fetal sex. Molecular techniques were used to determine sex in early stage fetuses, before gonadal differ- entiation, after validation of the method with known sexed late-stage fetuses and adults. Polymerase chain reaction (PCR) was used to test for the presence of $Y$-specific $S R Y$ gene in DNA extracted from samples of hyaena blood, amniotic fluid and cultured cells. Primers were based on the data of Sinclair et al. (1990) for human SRY gene taken from EMBL/GenBank databases: 5' (GAACGCATTCATCGTGTCGTC) and $3^{\prime}$ (TTCGGGTATTTCTCTCTGTGC). The PCR procedure was run for 40 cycles with the initial denaturation for 5 min at $94^{\circ} \mathrm{C}$, each subsequent denaturation for $30 \mathrm{~s}$ at $94^{\circ} \mathrm{C}$, the annealing for $30 \mathrm{~s}$ at $62^{\circ} \mathrm{C}$, and the termination of elongation for $5 \mathrm{~min}$ at $72^{\circ} \mathrm{C}$. The expected product is a 186 base pair DNA unique to the $\mathrm{Y}$-chromosome; hence, its presence and absence were used to identify males and females, respectively.

\section{Placental metabolism of steroids}

Steroid proAles in maternal and fetal circulations. Multiple timed blood samples were taken from various sites in the maternal circulation (cephalic vein, ovarian vein, uterine artery and vein) and from the umbilical artery and vein at various times during gestation (approximately 33-100 days) to extend information on placental metabolic activity in vivo. The general stability of peripheral concentrations, independent of changes after removal of placentae, indicates the lack of 'stress' responses in the anaesthetized females. Radioimmunoassays of plasma steroids $\left(\Delta^{4}\right.$-androstenedione, oestradiol, testosterone, and progesterone) were performed in ether-extracted samples as detailed by Licht et al. (1992). Testosterone antisera crossreacted with $5 a$-dihydrotestosterone, and oestrogen antiserum crossreacted with oestrone; dihydrotestosterone and oestrone 
have been measured independently in hyaenas (Licht et al., 1992).

Infusion of $\left[\left[^{3} \mathrm{H}\right]\right.$ androstenedione in vivo. $\left[{ }^{14} \mathrm{C}\right]$ Androstenedione (10 $\mu \mathrm{C} ; 55 \mu \mathrm{C} \mu \mathrm{mol}^{-1}$; NEN, Boston, MA) was infused into the uterine artery of a female containing mixed sex twins at 103 days of gestation (pregnancy G) to obtain direct evidence for metabolism and transport of maternal androstenedione across the placenta. Steroid was mixed with $20 \mathrm{ml}$ of serum from the same female. After a series of blood samples had been taken from the maternal circulation (cephalic vein, uterine artery and vein) and the umbilical artery and vein, $5 \mathrm{ml}$ of the radiolabelled steroid preparation was injected into the right uterine artery (this side was subsequently shown to contain a male fetus) and the remaining $15 \mathrm{ml}$ was infused over $20 \mathrm{~min}$ with a syringe. Heparinized blood samples from several veins were taken at intervals during and after infusion. Plasma was stored at $-70^{\circ} \mathrm{C}$ until analysed.

In a second test, $250 \mu \mathrm{C}\left[{ }^{3} \mathrm{H}\right]$ androstenedione (NEN: $1,2,6,7\left[{ }^{3} \mathrm{H}\right]$-androstenedione) mixed with $20 \mathrm{ml}$ serum was infused at $1 \mathrm{ml} \mathrm{min}^{-1}$ with a Harvard Syringe pump into the uterine artery of a female containing a single male fetus at about day 58 of gestation. Attempts to perform similar infusion at day 48 of gestation failed because of the difficulty in identifying a suitable uterine artery.

Plasma was obtained by centrifugation of the heparinized blood at $500 \mathrm{~g}$ for $5 \mathrm{~min}$ and extracted with ethyl acetate. Total d.p.m. and d.p.m. extracted from aliquots were determined using a Beckman LS-1801 scintillation counter. Radiolabelled metabolites in extracts were analysed by twodimensional thin layer chromatography (2d-TLC). Radioinert internal standards were added to the extract before application to a silica gel GF254 thin layer plate (Merck, Whitehouse Station, NJ). The plate was developed twice in one dimension using toluene:cyclohexane (1:1) and three times in benzene: ethyl acetate (3:1), and then once in a second dimension in chloroform:methanol:water (90:10:1). Radioactive spots corresponding to internal standards were localized using a Berthold TLC Scanner. Relative radioactivity in each spot was also confirmed by scraping, extraction with ethyl acetate and direct scintillation counting; the results were the same for the two methods.

Placental homogenates. The metabolism of androstenedione was measured in placentae derived from three pregnancies at days 48,58 and 78 of gestation (placental wet masses were 30 , 82 and $100 \mathrm{~g}$, respectively). A single term human placenta obtained from an uncomplicated delivery was used as a reference. Placentae were quick-frozen on dry ice and stored at $-70^{\circ} \mathrm{C}$. Enzymatic activity is not altered by freezing (Yalcinkaya ef al., 1993) and tissues collected in this manner showed no change in activity in repeated tests over several months of storage. Metabolic studies were modelled after those reported for homogenates of human and nearterm hyaena placentae (Yalcinkaya et al., 1993) with the following modifications: $1 \beta-\left[{ }^{3} \mathrm{H}\right]$-androstenedione (NEN, $\left.24.1 \mu \mathrm{C} \mathrm{mmol}^{-1}\right)$ was used as substrate instead of $19-\left[{ }^{3} \mathrm{H}\right]$ androstenedione; and $10 \mathrm{iu}$ glucose-6-phosphate dehydrogenase was used in the NADP-generating system instead of $100 \mathrm{iu}$, after pilot tests showed that this was well above required concentrations. Placental tissues were minced, homogenized, and large particulate matter was removed by low speed spin in buffer with glucose. Aliquots were then

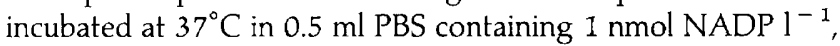
$10 \mathrm{mmol}$ glucose-6-phosphate $\mathrm{l}^{-1}$ and $10 \mathrm{iu}$ glucose-6phosphate dehydrogenase (all reagents from Sigma, St Louis, MO). Approximately $0.5 \mathrm{Ci}$ radiolabelled androstenedione was added alone or with various concentrations $\left(0-2500 \mathrm{nmol} \mathrm{l}^{-1}\right)$ of radioinert androstenedione. Preliminary tests on tissue concentration and time were undertaken to establish the protein concentration at which enzyme activity was linear for at least $20 \mathrm{~min}$ at $37^{\circ} \mathrm{C}$. All calculations were then performed after $10 \mathrm{~min}$ incubation.

Aromatase activity was assessed radiometrically by the production of labelled $\mathrm{H}_{2} \mathrm{O}$ (Miyairi and Fishman, 1985). At the end of incubation, incubates were extracted twice with $2 \mathrm{ml}$ ethyl acetate and the resulting nonextracted (aqueous) phase was incubated with $250 \mu \mathrm{l}$ dextran-coated charcoal $(2.5 \%$ charcoal, $0.25 \%$ dextran) on ice for $60 \mathrm{~min}$ to remove residual steroids. Aliquots of the aqueous phase were then counted to determine the concentrations of $\left[^{3} \mathrm{H}\right]_{2} \mathrm{O}$. Dehydrogenase activity was assessed by the production of testosterone which was determined by TLC analysis of the organic extracts. Aliquots of the ethyl acetate extract were analysed by 2D-TLC as detailed above. The protein content of tissue homogenates was determined by the Bradford reagent (BioRad) using BSA as standard.

An aromatase inhibitor, Fadrazole (CGS 16949A; a gift from Ciba-Geigy, Summit, NJ and Basel, Switzerland), was used to examine androgen production in the absence of oestrogen production in the day 48 placenta. Incubations were as described above, but $200 \mu \mathrm{mol}$ Fadrazole $1^{-1}$ was added to a parallel series of tubes containing variable concentrations of radioinert androstenedione. Preliminary tests showed no difference in responses between this dose and one at half this concentration.

Whole placenta. In the case of the day 48 pregnant hyaena, metabolism of one of the two placentae was also examined immediately after removal by injecting $100 \mu \mathrm{C}\left[{ }^{3} \mathrm{H}\right]$ androstenedione mixed in saline into multiple sites of the intact organ. The whole placenta was incubated for $10 \mathrm{~min}$ in Dulbecco's modified Eagles medium at $35^{\circ} \mathrm{C}$. It was then frozen, pulverized in liquid $\mathrm{N}_{2}$, extracted and analysed by 2D-TLC as described above.

\section{Results}

\section{Development of the urogenital system in early gestation}

Determination of fetal sex. PCR products from adult male and female hyaenas and fetuses that were developed enough to sex morphologically were consistent with the expected presence and absence, respectively, of a 186 bp product (Fig. 1); several larger products $(600-900 \mathrm{bp})$ were not sex specific. On the basis of the absence of the expected specific product after PCR, the youngest, 33 day fetus was judged to be female (Fig. 1: fetus 4 , pregnancy A). The twin fetuses in pregnancy $\mathrm{B}$ were also judged to be female on the basis of the absence of this 


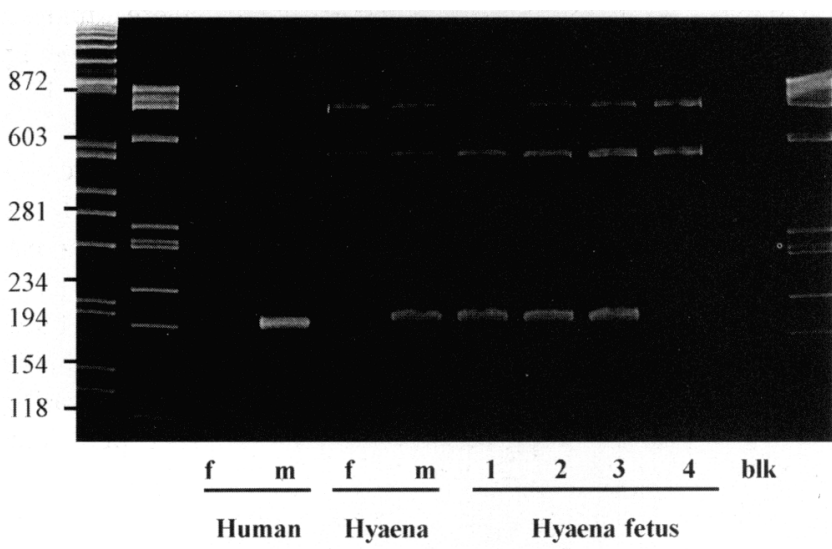

Fig. 1. Polymerase chain reaction of the $Y$-specific $S R Y$ gene in hyaena lymphocytes or amniocytes. A 186 base pair length of DNA is produced when a $Y$ chromosome is present. Note the positive band for the adult male $(\mathrm{m})$ control and its absence in the adult female ( $\mathrm{f}$. Amniocenteses 1,2 and 3 were also judged to be male by morphological examination. A I kb DNA ladder is shown at both ends and a ФX DNA ladder is shown in lane 2: estimates of fragment size (bp) are indicated on the left.

genetic marker (data not shown), while the fetus resulting from pregnancy $C$ was judged to be male as indicated by the presence of the $186 \mathrm{bp}$ product (Fig. 1: fetus 1).

Urogenital development in a 33 day female fetus. The gonads of the one 'female' hyaena fetus at day 33 of gestation were undifferentiated, having neither testicular cords nor welldefined ovarian follicles (Fig. 2a). The Wolffian duct extended the full length of the urogenital ridge, terminating caudally at the urogenital sinus and exhibiting ductal connections (mesonephric ducts) to a mesonephros (Fig. 2b). The mesonephros was at least twice the size of the gonad, and the adrenal gland was even larger than the mesonephros, having an extensive, densely cellular zone centrally surrounded by an undifferentiated, sparsely populated peripheral zone (Fig. 2d). The Müllerian ducts were present cranially within the urogenital ridge (Fig. 2b), but extended only about $75 \%$ of the length of the urogenital ridge. Thus, in the cranial region, the Wolffian and Müllerian ducts were present side by side (Fig. 2b) whereas, near the urogenital sinus, only the Wolffian duct was observed in transverse sections (Fig. 2c). The genital tubercle viewed externally was prominent and $2.2 \mathrm{~mm}$ in length, that is, $56 \%$ the length of the tail (Fig. 2e). A solid urethral plate was present along the entire length of the genital tubercle from the urogenital sinus to the tip of the phallus (Fig. 2f). Dense mesenchymal tissue surrounding the urethra represented the future erectile bodies.

Urogenital development at days 4850 of gestation. As noted above, the two 48-day-old fetuses (pregnancy B) were judged to be female, while the single day 50 fetus (pregnancy C) was judged to be male, with confirmation of the latter by the gross morphology (Fig. 3a,d,e) and histology of the gonads (Fig. 3c,f). A diagnostic feature distinguishing the ovaries of the day 48 specimens from the testes of the day 50 specimen was the overall gross shape of the gonads, that is, the ratio of length to width. Ovaries of the day 48 specimens were about half of the size of the mesonephros (Fig. 3a) and had an elongated morphology with a length to width ratio of 0.512 . Histologically, the gonads of the day 48 female specimens lacked seminiferous cords or definitive ovarian follicles, having a nondescript undifferentiated appearance (Fig. 3c). By contrast, the testes of the day 50 male specimen had a plump, rounder morphology (Fig. 3d,e) with a length to width ratio of about 0.625 , and contained seminiferous cords (Fig. $3 \mathrm{f}$ ).

For the day 48 female fetuses and the day 50 male fetus, wholemount photography showed the presence of both Wolffian and Müllerian ducts in the urogenital ridge (Fig. 3a,d,e). Mesonephric tubules were observed connecting the Wolffian duct to a mesonephros that was about twice the size of the ovary (Fig. 3a). The mesonephros of the male fetus was slightly smaller than the testis (Fig. $3 \mathrm{~d}$,e). The Wolffian and Müllerian ducts terminated at the urogenital sinus in both the male and female fetuses. The upper urogenital sinus extended caudally and terminated externally as the clitoris or penis, as appropriate, which were of similar size (Fig. 3b,d). A urethra was present along the entire length of the clitoris and penis from the urogenital sinus to the tip of the phallus. Condensations of mesenchymal tissue represented the future erectile bodies in both the clitoris and penis (Fig. 4). Thus, the clitoris and penis were remarkably similar in size and morphology in these male and female fetuses very close in gestational age.

\section{Placental steroid metabolism}

Steroid gradients. Steroid gradients resulting from placental metabolism were studied in five pregnancies, interrupted at gestational ages ranging from 33 to 103 days. In all cases, observations confirmed earlier results obtained on near-term animals concerning the source of androgens and oestrogen. Systemic concentrations of the steroids measured (oestrogen, progesterone, testosterone, and androstenedione) in the maternal circulation (cephalic vein) generally increased as pregnancy progressed. Uterine gradients observed during one early (day 48) and one late (day 78 ) pregnancy are shown (Figs 5 and 6, respectively). In these two, as well as in day 33, 64 and 101 pregnancies (data not shown), plasma testosterone concentrations increased in association with a decrease in androstenedione across the placenta (uterine artery-uterine vein gradients). Concentrations of oestrogen and progesterone were also markedly increased across the uterus (data not shown). In each case, these gradients disappeared (for example, uterine vein testosterone decreased and androstenedione increased) after removal of the fetal-placental unit (for example see Figs 5 and 6). A mixed blood sample taken from the cut surface of the ovary at day 33 (pregnancy A) had markedly increased androstenedione (100 ng mil ${ }^{-1}$ compared with $4.7-9.0 \mathrm{ng} \mathrm{ml}^{-1}$ in the maternal cephalic vein), but the concentrations of other steroids were comparable with those in the cephalic vein.

Owing to the small size of the relevant blood vessels or to premature detachment of the fetus from the placenta, difficulties were encountered in obtaining blood samples from either the fetus or the umbilical circulation during earlier cross-sections. However, testosterone concentrations were 

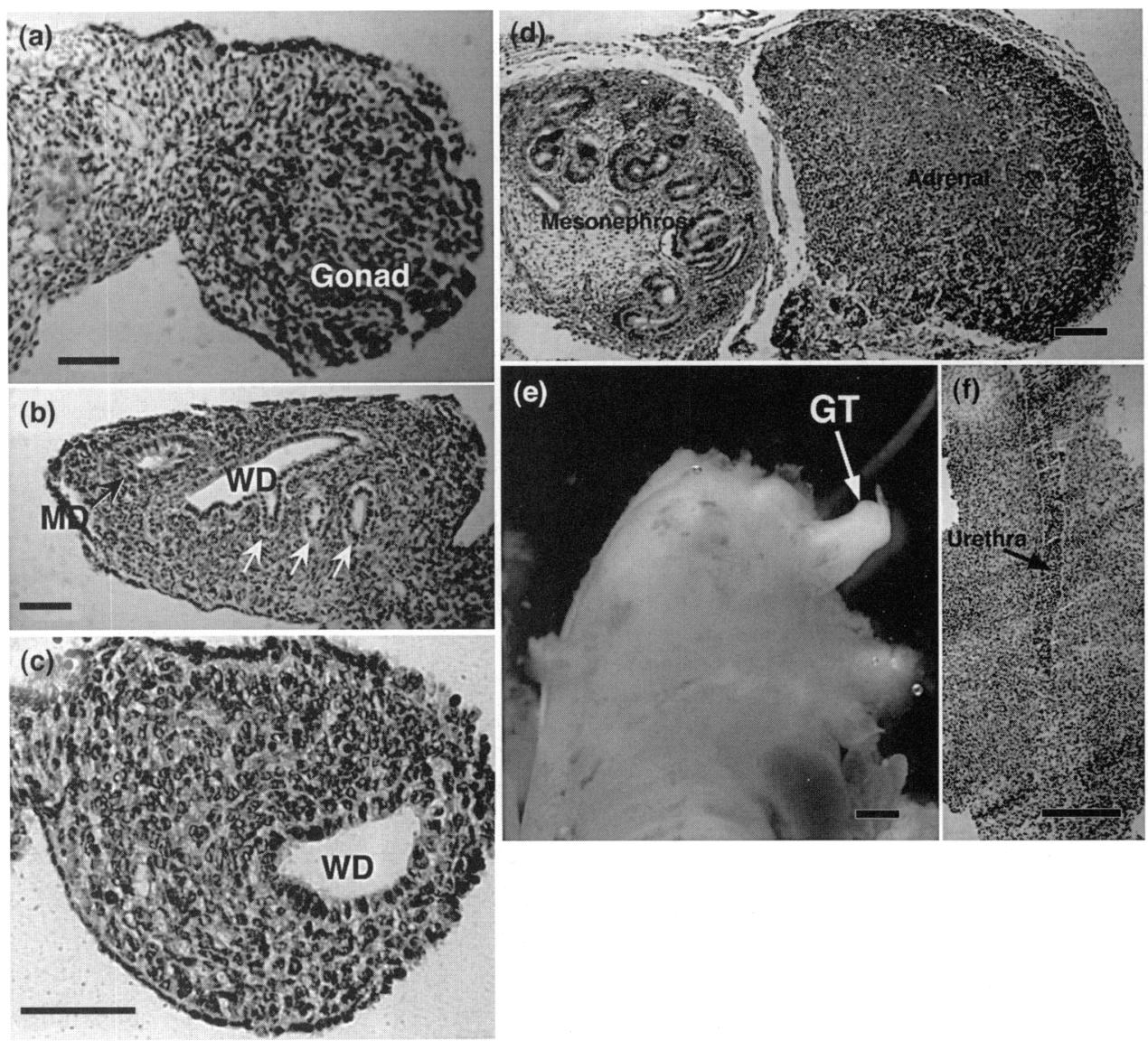

Fig. 2. Urogenital development in the female spotted hyaena fetus at day 33 of gestation. (a) Transverse section of the undifferentiated gonad. (Mesonephros not shown in (a) is located to the left of the figure). (b) Section of the upper urogenital ridge showing Müllerian duct (MD) and Wolffian duct (WD). Note mesonephric tubules (white arrows) extending from the Wolffian duct to the mesonephros, which is out of the plane of section. (c) Transverse section of the lower urogenital ridge showing Wolffian duct (WD) only. Note the absence of the Müllerian duct. (d) Longitudinal section of the mesonephros and adrenal gland. (e) Side view of the caudal half of a female spotted hyaena fetus at day 33 of gestation. The rump is at the top of the figure. The legs and tail have been surgically removed to obtain an unobstructed view of the genital tubercle (GT). (f) Longitudinal section of the genital tubercle showing a solid urethral plate and surrounding condensed mesenchyme. Scale bars represent (a-c) $50 \mu \mathrm{m},(\mathrm{d}, \mathrm{f}) 100 \mu \mathrm{m}$, and (e) $1 \mathrm{~mm}$.

consistently $>\mathrm{Ing} \mathrm{ml} \mathrm{m}^{-1}$ in the few samples obtained from either the fetal heart (10 $\mathrm{ng} \mathrm{ml} \mathrm{ml}^{-1}$ at 50 days and $5.6 \mathrm{ng} \mathrm{ml}^{-1}$ at 78 days) or the umbilical vein (see Figs 5 and 6). These concentrations were higher than (for example, Fig. 6) or about the same as (for example, Fig. 5) those in the maternal cephalic vein, whereas oestrogen was consistently low in the fetal heart, indicating its rapid metabolic clearance in the fetus.

Infusion of radiolabelled androstenedione into uterine artery. Infusion of radiolabelled androstenedione into the maternal uterine artery provided the most complete data set in a late term pregnancy (103 days; pregnancy G). Extractable label was detected in the uterine vein $4 \mathrm{~min}$ after the start of the infusion and in the umbilical vein 15 min after the initiation of infusion of $\left[{ }^{1+} \mathrm{Clandrostenedione} \mathrm{into} \mathrm{the} \mathrm{uterine} \mathrm{artery} \mathrm{(Fig.} \mathrm{7).} \mathrm{In} \mathrm{both}\right.$ sites, $90-95 \%$ of total counts were recovered in the organic phase after extraction throughout the infusion. Total radio- activity and the percentage extractable fell progressively after termination of infusion (for example, to $45 \%$ of total counts at $60 \mathrm{~min}$ ), but was still detectable in the umbilical vein for up to $1 \mathrm{~h}$. Radioactivity in the maternal cephalic vein was too low (about 16-fold lower than in the uterine vein) for further analysis.

Data from TLC analyses of uterine and umbilical samples are summarized (Table 2). All of the starting tracer (incubated in serum overnight at room temperature) comigrated with authentic unlabelled androstenedione; that is, it was not metabolized in serum. In uterine vein extracts, radioactivity co-migrated with at least seven reference compounds plus several unidentified spots, but the vast majority migrated as testosterone and $17 \beta$-oestradiol $(65 \%$ and $32 \%$, respectively, of total recovered radioactivity); no remaining labelled androstenedione was detected in the uterine vein. In the umbilical sample, the low radioactivity limited detection of minor 

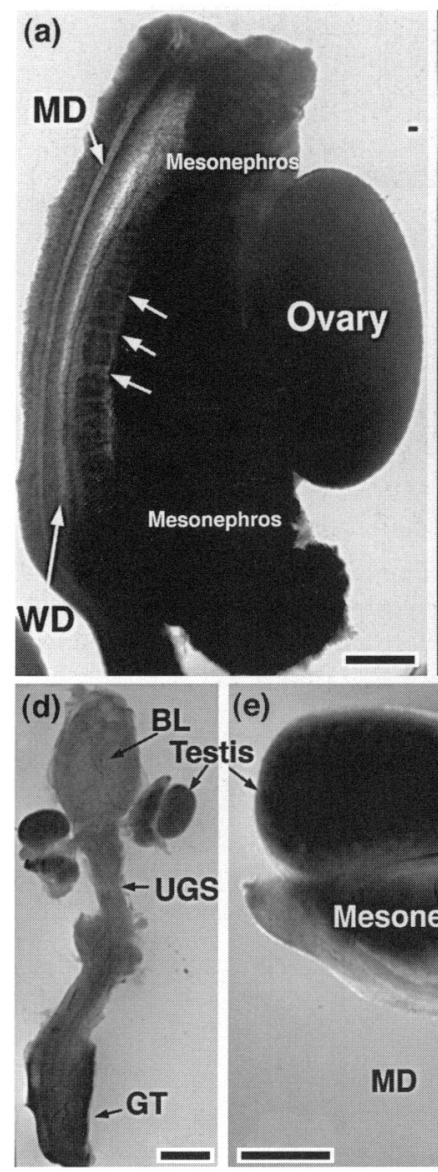
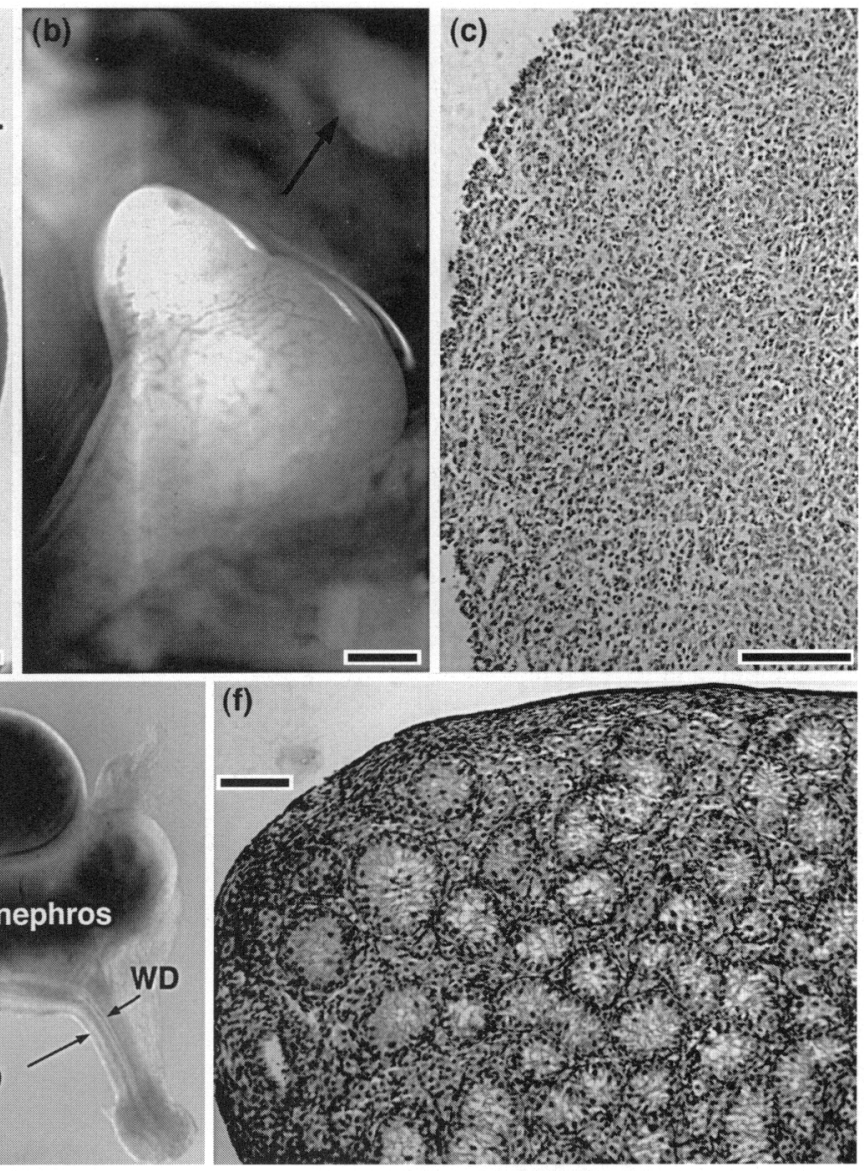

Fig. 3. Urogenital development in $(a-c)$ female spotted hyaena fetuses at day 48 of gestation and $(d-f)$ male spotted hyaena fetuses at day 50 of gestation. (a) Wholemount image of a day 48 female urogenital tract showing the Müllerian duct (MD), Wolffian duct (WD) and associated mesonephric tubules (arrows). Note that the mesonephros is considerably larger than the ovary. (b) Side view of the genital tubercle. The arrow denotes the caudal direction. (c) Transverse section of the ovary, which is undifferentiated. (d) Wholemount image of the entire urogenital tract of a day 50 male fetus showing bladder (BL), upper urogenital sinus (UGS), and genital tubercle (GT). The structure associated with the testis is a rather large mesonephros (not labelled). (e) Higher magnification of the upper genital tract showing Müllerian duct (MD), Wolffian duct (WD), testis, and large mesonephros. (f) Transverse section of the testis showing well developed seminiferous tubules. Scale bars represent (a) $500 \mu \mathrm{m}$, (b) $1 \mathrm{~mm},(\mathrm{c}, \mathrm{e}) 100 \mu \mathrm{m}$, (d) $250 \mu \mathrm{m}$, and (f) $50 \mu \mathrm{m}$.

components and only testosterone (51\%) and oestrogen (49\%) were identified.

Labelled androstenedione was also infused in the maternal uterine circulation during termination of pregnancy $D$ at day 58 of gestation. Although it was not possible to obtain umbilical vein samples, results from uterine vein samples demonstrated the metabolism of the $\left.\right|^{3} \mathrm{H}$ androstenedione infused into the uterine artery. In this plasma, $85 \%$ of the radioactivity was extractable: $11 \%$ of the extractable label was identified as androstenedione, $52.8 \%$ as oestrogen and $22.7 \%$ as testosterone. These values presumably reflect the combination of placenta plus peripheral metabolism and clearance of the infused label.

Metabolism of androstenedione in vitro: placental homogenates. The aromatase activities of the day 48 and 58 hyaena placentae were similar and several-fold higher than that of the older, day
78, placenta (Fig. 8 and Table 3). Younger placentae also produced the most testosterone, but $V_{\max }$ values differed only slightly. Apparent $V_{\max }$ values for testosterone production were 10-35-fold higher than for aromatase production, with the greatest difference found in the day 48 placenta (Table 3 ). The human placental homogenate had markedly higher aromatase activity but no testosterone production was measurable (Fig. 9).

Addition of the aromatase inhibitor, Fadrazole, effectively blocked the production of oestrogen in both hyaena and human tissues as determined by the absence of radioactivity in the aqueous phase of the incubates. However, the inhibitor reduced the degradation of androstenedione only at the lowest substrate concentrations $\left(<200 \mathrm{nmol} \mathrm{l}^{-1}\right.$ ) and had no effect on testosterone production at any concentration in the hyaena tissue (Fig. 9). In contrast, in parallel tests with human tissue, Fadrazole markedly decreased the proportion of labelled 

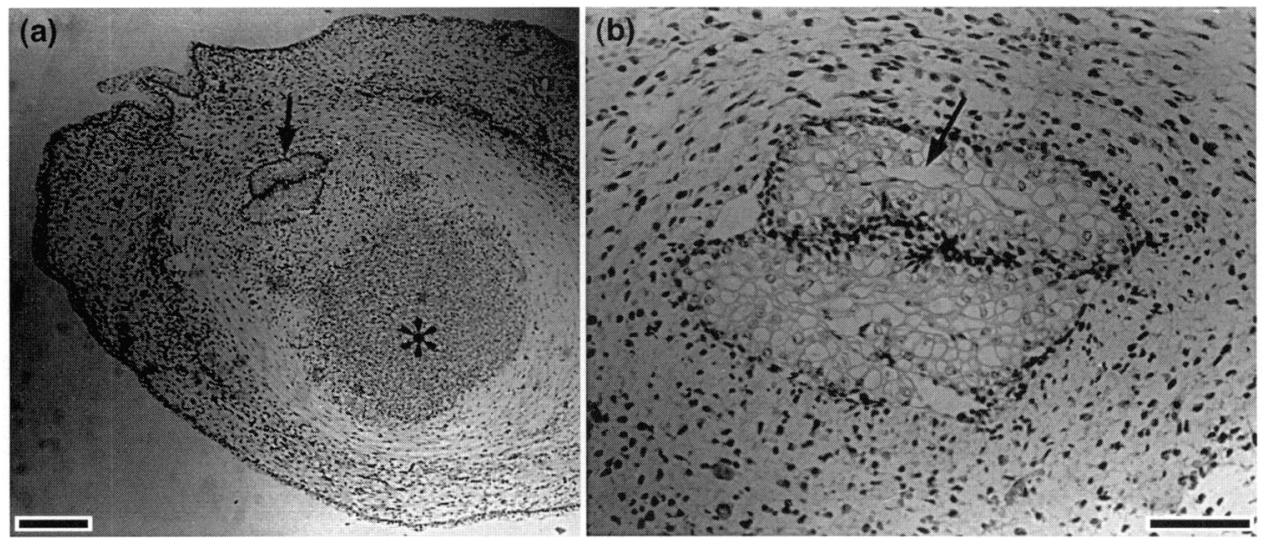

Fig. 4. Transverse section of the clitoris of a female fetus at day 48 of gestation. In (a) note the urethral plate (arrow) and condensed mesenchyme representing developing erectile tissue (asterisk). (b) Higher magnification of the clitoris shows the beginning of lumen formation (arrow). Scale bars represent (a) $200 \mu \mathrm{m}$, and (b) $50 \mu \mathrm{m}$.
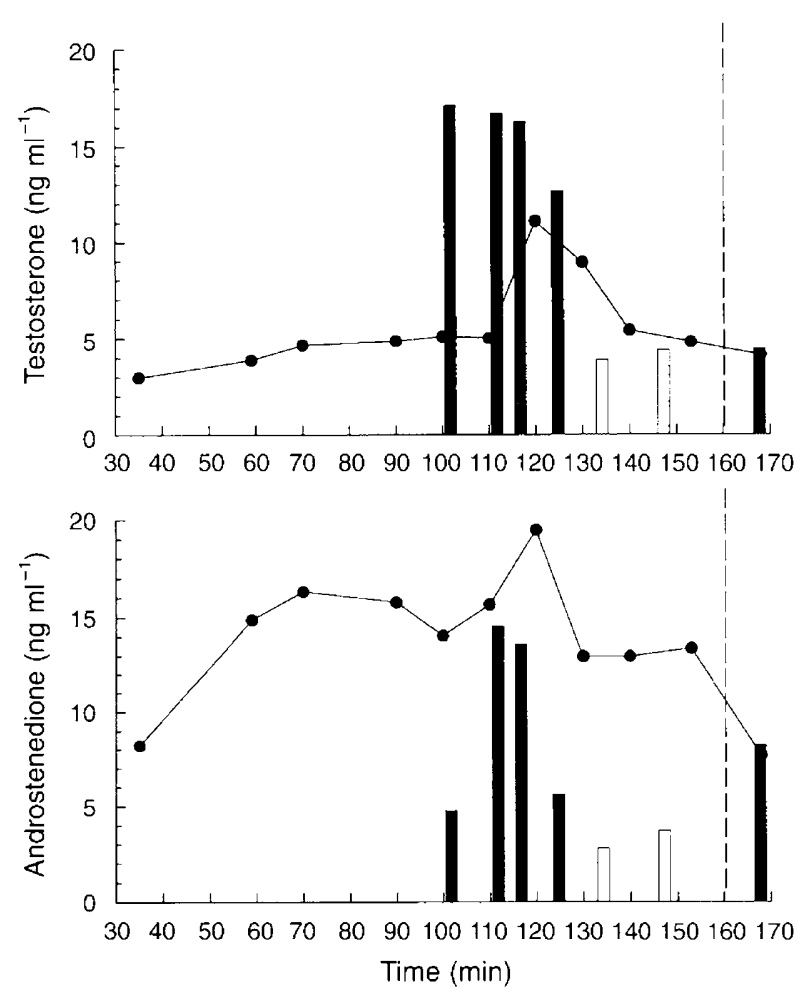

Fig. 5. Steroid profiles in maternal circulation showing the gradient across the placenta (cephalic vein $(\mathbf{O})$ versus uterine vein $(\mathbf{\square})$ ) and in the umbilical vein $(\square)$ of a hyaena at day 78 of gestation at various times after anaesthesia. The incision into the uterus to expose the fetus was made at about $130 \mathrm{~min}$, and the fetal-placental unit was removed at $160 \mathrm{~min}$ (vertical dashed line).

substrate metabolized at all concentrations and increased testosterone production over a wide range of substrate concentrations (Fig. 9).

Metabolism of androstenedione in vitro: whole placente. TLC analysis of radioactivity in a whole placenta, obtained at day 48 of gestation and incubated with $\left[{ }^{3} \mathrm{H}\right]$ androstenedione for
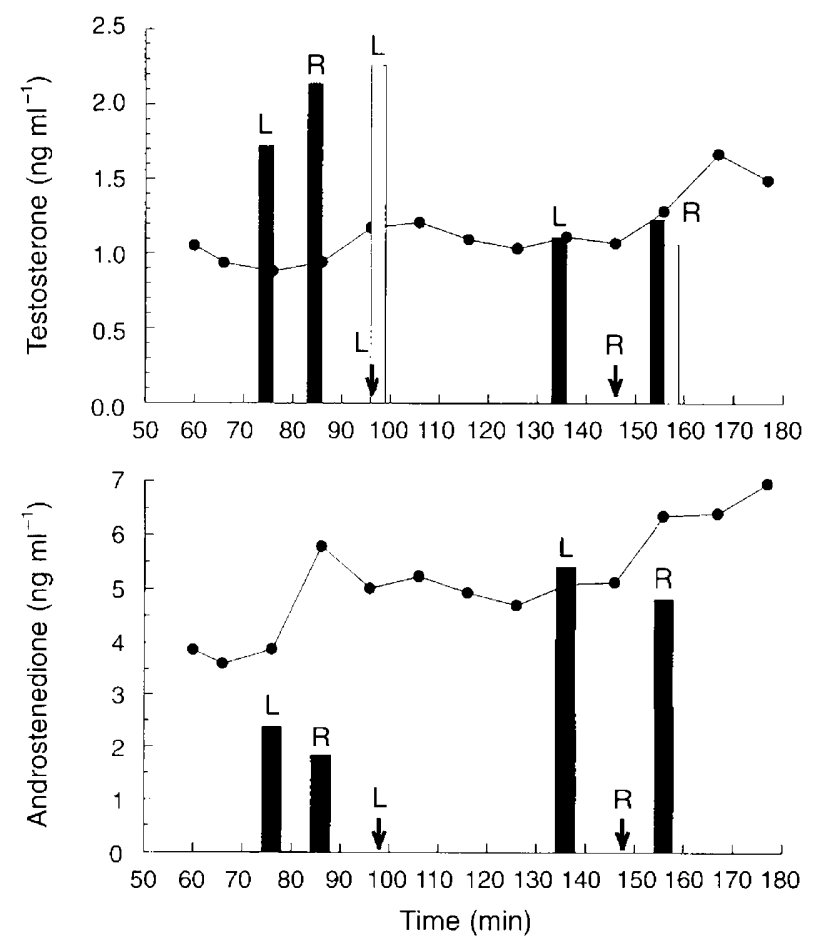

Fig. 6. Steroid profiles in maternal circulation showing the gradient across the placenta (cephalic vein $(\mathbf{O})$ versus uterine vein $(\boldsymbol{\square})$ ) and in the umbilical vein $(\lceil)$ of a hyaena at day 48 of gestation at various times after anaesthesia. Female had twins determined to be females by PCR. Both left (L) and right (R) uterine and umbilical veins were sampled; arrows with same letters indicate the time of removal of the two fetal-placental units.

10 min showed that about $92 \%$ of the label was metabolized. Twelve spots were distinguished, but radioactivity comigrating with oestrogen and testosterone ( 35 and $25 \%$ of total d.p.m., respectively) comprised the two major metabolites. The ten remaining individual metabolites represented $2-7 \%$ of the total c.p.m. extracted; the two most abundant comigrated with $5 \beta$-androstan, $3 \alpha$-OL-17-one $(4.8 \%)$ and $5 \beta$-androstan, 3,17 dione $(6.4 \%)$. 


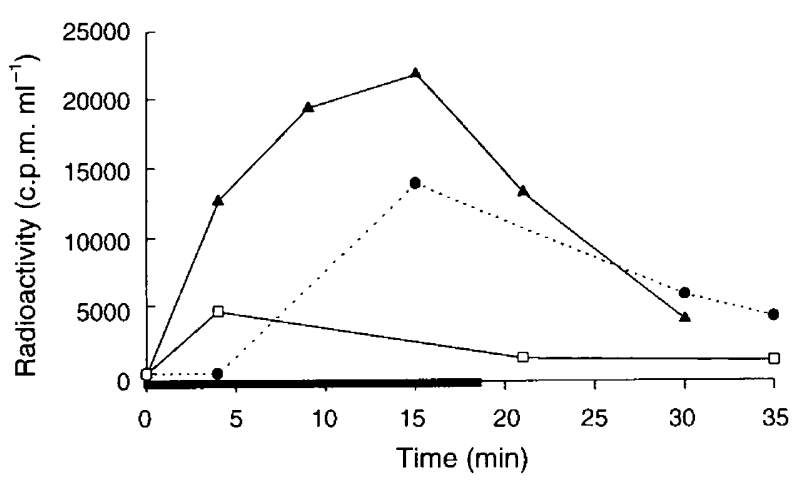

Fig. 7. Appearance of radioactivity in maternal and fetal circulation after the start of infusion of $\left[{ }^{14} \mathrm{C}\right]$ androstenedione at day 78 of gestation. ( $\Delta$ ) Uterine vein; ( $)$ umbilical vein; and $(\square)$ cephalic vein. Infusion was for approximately $18 \mathrm{~min}$ (heavy bar). Counts were determined in aliquots of unextracted plasma; $>90 \%$ of counts were extractable by organic solvent during infusion.

Table 2. Two-dimensional TLC analysis of plasma extracts from female hyaena infused with $\left[{ }^{14} \mathrm{C}\right] \Delta^{4}$ androstenedione at day 78 of gestation

\begin{tabular}{lccc}
\hline & \multicolumn{3}{c}{$\begin{array}{c}\text { Percentage of } \\
\text { total counts recovered* }\end{array}$} \\
\cline { 2 - 4 } Steriod & $\begin{array}{c}\text { Uterine } \\
\text { vein }\end{array}$ & $\begin{array}{c}\text { Umbilical } \\
\text { vein }\end{array}$ & Label** $^{* *}$ \\
\hline Androstenedione & 0.9 & 0 & 100 \\
Dihydrotestosterone & 0.1 & 0 & 0 \\
1-Hydroxytestosterone & 0.21 & 0 & 0 \\
Oestradiol & 31.7 & 49.0 & 0 \\
Testosterone & 65.2 & 51.0 & 0 \\
Unidentified (>2 c.p.m.) & 2.0 & 0 & 0 \\
\hline
\end{tabular}

Plasma samples were taken after 15-20 min of infusion.

*Spots corresponding to authentic internal standards were scraped and counted. The same results were obtained from direct scanning of the plate.

**Represents a sample of the infused steroid incubated in plasma

\section{Discussion}

At day 33 of gestation (earliest stage examined), the genital tubercle of the female spotted hyaena fetus is exceptionally prominent and appears to be fully 'masculinized', having a urethral plate that occupies the entire length of the tubercle. At this point, the female fetus is in an ambisexual stage: histologically, the gonad is small and undifferentiated (neither ovarian follicles nor seminiferous cords are present) and the primitive nature of the urogenital tract is manifested by the incomplete formation of the Müllerian ducts. At an estimated day 48 of gestation (pregnancy B), the ovaries are still not differentiated, although in an only slightly older male fetus (about 50 days: pregnancy $\mathrm{C}$ ), the clear presence of seminiferous cords indicates that gonadal differentiation has already occurred. The primitive condition of the fetal ovary at a time when there is a well-formed, growing, penile clitoris suggests that the fetal ovary cannot be responsible for the masculine form of the hyaena clitoris, as originally suggested by Racey

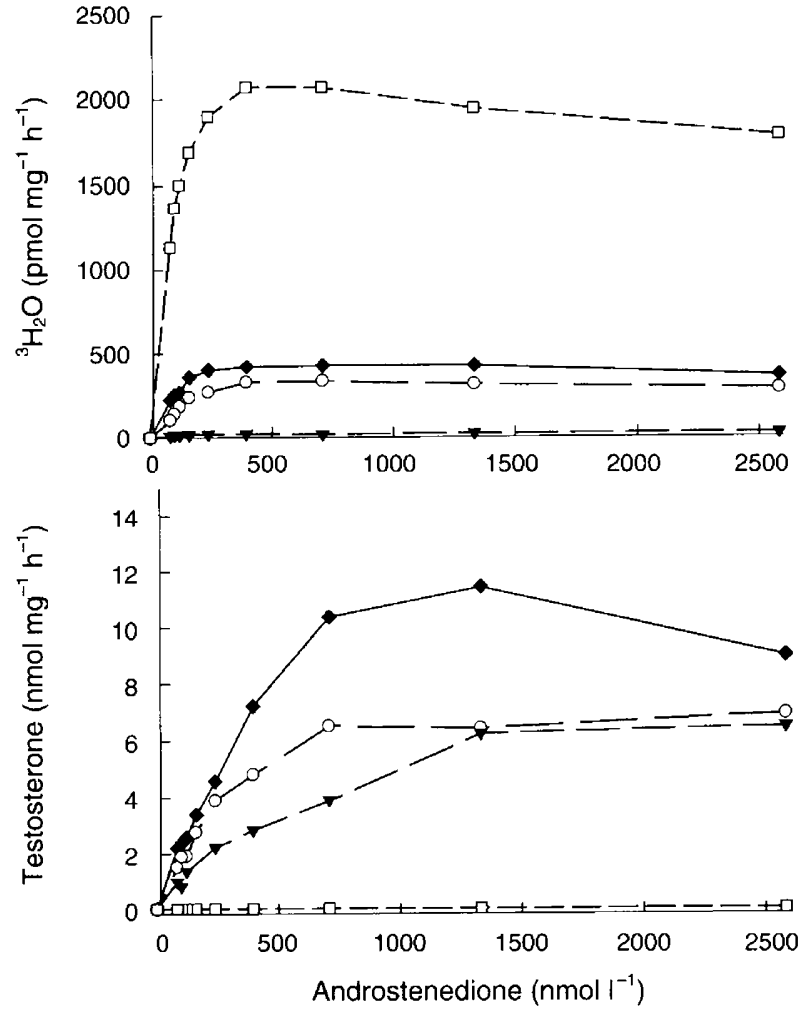

Fig. 8. (a) Aromatase activity (measured by production of $\left[{ }^{3} \mathrm{H}\right]_{2} \mathrm{O}$ ) and (b) 17ß-hydroxysteroid dehydrogenase (measured by testosterone production) in placental homogenates of spotted hyaena from days 48 $(\diamond), 58(\bigcirc)$ and $78(\boldsymbol{\nabla})$ of gestation and a term human placenta $(\square)$.

Table 3. Characteristics of steroidogenic enzymes in hyaena placental homogenates

\begin{tabular}{|c|c|c|c|c|}
\hline \multirow{2}{*}{$\begin{array}{l}\text { Gestation } \\
\text { age } \\
\text { (days) }\end{array}$} & \multicolumn{2}{|r|}{ Aromatase* } & \multicolumn{2}{|c|}{$\begin{array}{l}\text { 17ß-Hydroxysteroid } \\
\text { dehydrogenase** }\end{array}$} \\
\hline & $\begin{array}{c}K_{\mathrm{m}} \\
(\mathrm{nmol})\end{array}$ & $\left(\begin{array}{c}V_{\max } \\
\left(\mathrm{nmol} \mathrm{mg}^{-1} \mathrm{~h}^{-1}\right)\end{array}\right.$ & $\underset{(\mathrm{nmol})}{K_{\mathrm{mn}}}$ & $\left(\right.$ nmol mg $\left.{ }^{-1} \mathrm{~h}^{-1}\right)$ \\
\hline 48 & 183 & 0.63 & 457 & 22.4 \\
\hline 58 & 130 & 0.514 & 224 & 9.9 \\
\hline 78 & 67 & 0.47 & 361 & 5.1 \\
\hline
\end{tabular}

*Aromatase measured by production of $\left[{ }^{3} \mathrm{H}\right]_{2} \mathrm{O}$

**Measured by production of testosterone.

and Skinner (1979). Renfree and Short (1988) have presented an analogous argument with regard to differentiation of the scrotum of the tammar wallaby that the fetal testes cannot be responsible for differentiation of the wallaby scrotum, since it is formed before histological differentiation of the testes.

More precise data on when differentiation of the seminiferous cords is first apparent in the male fetus would be useful. From the data on pigs, it is likely that the testes differentiate before day 33 , when the female is still ambisexual (Ford et al., 1980). The pig offers a useful comparison for genital development in hyaenas because of the similarity in their gestation periods (113 versus 110 days) and general body size 


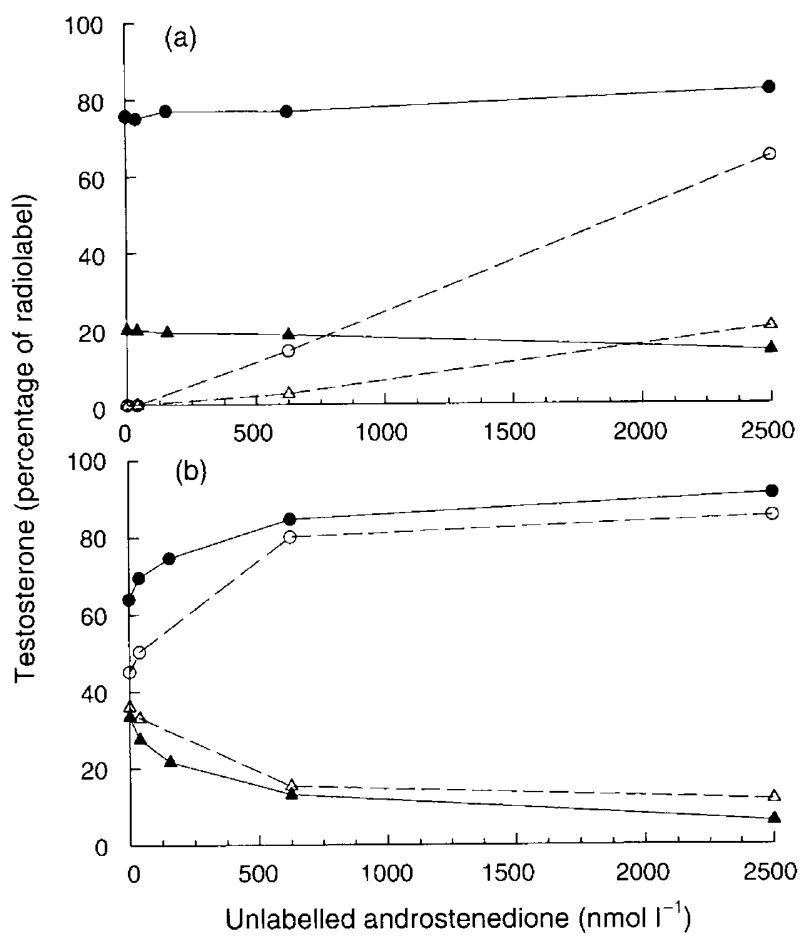

Fig. 9. Effects of Fadrazole $\left(\boldsymbol{\Lambda}, \mathbf{\Delta}: 200 \mu \mathrm{mol} \mathrm{l}^{-1}\right)$ on the metabolism of labelled androstenedione $(O, \mathbf{O})$ and the production of testosterone $(\triangle, \boldsymbol{\Lambda})$ by (a) human placenta (512 $\mu \mathrm{g}$ protein) and (b) day 48 hyaena placenta (103 $\mu \mathrm{g}$ protein) in the presence of increasing concentrations of radioinert androstenedione. Values show the percentage of the two compounds in the total radioactivity recovered from ethyl acetate extracts of incubation media. Note that a larger proportion of the initial substrate was aromatized by control tissues $(0, \Delta)$ and that the total aromatase activity in the human tissue was severalfold higher than in the hyaena.

at birth (Ford et al., 1980). In pigs, the genital tubercle of male fetuses enlarges by day 38 to form the penis, mesenephroi reach maximal size in both sexes by day 40 , and the genital ducts differentiate morphologically by day 55 . Sex differences are greatest at day 35, presumably due to the onset of testicular androgen secretion (measured in vitro) around days 32-36 (histologically, the testis is differentiated at day 26), while ovaries remain inactive (male testosterone concentrations are approximately $4 \mathrm{ng} \mathrm{ml}^{-1}$ compared with $0.2 \mathrm{ng} \mathrm{ml}^{-1}$ in females). Thus, the 'masculine' condition of the genitalia in day 33 hyaena female fetuses already resembles that of male pigs at this stage.

Convergent evidence from an array of different measurement procedures indicates that placental metabolism and secretion of testosterone from ovarian-derived plasma androstenedione occurs throughout (at least) the last two-thirds of gestation. Studies of endogenous steroid gradients across the uterus, infusion of labelled androstenedione into the uterus, and in vivo metabolic activity of placental tissues, combined with morphological observations of fetal genital development, show that placental conversion of androstenedione to testosterone occurs early in female urogenital development and continues throughout gestation. These results extend previous studies of near-term placental metabolism (Yalcinkaya et al., 1993) to much earlier periods of gestation.
The results of the infusion of radiolabelled androstenedione at days 58 and 103 of gestation provide additional direct evidence that androstenedione in the maternal circulation is metabolized to testosterone as well as to oestrogen; these two steroids comprise the two major metabolites of androstenedione. Data obtained from the infusion of androstenedione into the maternal uterine artery provide direct evidence that both metabolites are transferred across the placenta to the developing fetus, with androgen representing a major secretory product of the placenta. The results from the infusion at day 58 of gestation are more difficult to interpret in relation to the fetus because of the apparent selection of uterine vessels for infusion and sampling that did not drain the placental area; however, the results are still consistent with the placental conversion of androstenedione to oestrogen and testosterone by the placenta. Neither the metabolic studies in vivo nor the studies in vitro with placental tissues showed the production of measurable dihydrotestosterone, which is almost equimolar with testosterone in the circulation of pregnant female hyaenas (Licht $e t$ al., 1992); this steroid is presumably derived from other peripheral reductase activity.

The most striking feature of the hyaena placenta is its production of large amounts of testosterone that enter both the maternal and fetal circulations, so that there is little difference between general androgen exposure of male and female fetuses (these data do not rule out the possibility that there are higher localized testosterone concentrations in males owing to additional testicular contributions). Several cases of genital masculinization in women have been attributed to placental aromatase deficiency (Shozu et al., 1991; Ito et al., 1993; Conte et al., 1994), which presumably results in excessive transfer of androgen to the developing female fetus. The appearance of these human cases offers support for the hypothesis that masculinization of the female hyaena is the result of testosterone transferred from the placenta. The relatively low aromatase activity in hyaenas compared with that in humans may account, in part, for the higher net androgen production, although hyaenas are not aromatase deficient to the extent of the cases of genital masculinization in women. For example, complete suppression of aromatase (by Fadrazole) has little effect on testosterone production in hyaenas whereas it has a large effect in humans. However, even when aromatase was fully suppressed, human placental homogenates did not produce as much testosterone from androstenedione metabolism as did normal hyaena tissue (Fig. 9). Contrary to earlier reports (Yalcinkaya et al., 1993), significant testosterone production was not detected in human placentae, except when the aromatase was fully blocked. The present results are consistent with metabolic studies on minced rhesus monkey placentae, in which little testosterone but substantial amounts of oestrogen were synthesized from radiolabelled androstenedione after the luteal-placental shift (Ellinwood et al., 1989); there is no direct evidence to support a change in placental function associated with a luteal-placental shift in hyaenas.

The hyaena is also distinct from ungulates like sheep (Harvey et al., 1972) and cows (Gross and Williams, 1988), in which testosterone is not produced from androstenedione by placental tissue in vitro. Unfortunately, there are no comparative data for phylogenetically more relevant species and, in particular, the three other hyaenid species that show more 
normal female external genital development. Thus, the degree to which ovarian androstenedione production and placental androgenesis have diverged to produce the 'anomalous' masculinization remains to be determined. It is not known whether the low aromatase in hyaena results simply from quantitatively low concentrations or genetic 'defects' of the aromatase, as in the human cases (Ito et al., 1993; Conte et al., 1994).

There are several respects in which the results of the present study apparently contradict the pioneering work of Lindeque and Skinner (1982), who have published the only other observations of urogenital morphology and androgen concentrations in fetal hyaenas. First, with regard to morphology of the fetal ovary, Lindeque and Skinner (1982, p. 407) suggest that the ovary is well differentiated at a gestational age of " 50 days", and note the presence of "... numerous large vacuolated cells in the primary germinal cords of the ovarian medulla ... These cells resembled the interstitial cells associated with the primary and secondary germinal cords of the fetal testis ...", leading them to suggest that "... masculinization of the genital tubercle of female fetuses results, as in the male, from an episode of androgen secretion by the fetal gonad." However, Lindeque and Skinner were forced to rely on the Huggett and Widdas growth equation (Huggett and Widdas, 1951; Frazer and Huggett, 1974) for estimating fetal age. Reversing the procedure, it can be inferred that Lindeque and Skinner were studying a fetus weighing $48.23 \mathrm{~g}$ to estimate fetal age at 50 days. It is clear that this mass is achieved significantly later in gestation than the day 48 female fetuses in the present study, with age assigned on the basis of the midpoint criterion (pregnancy B). These twin female fetuses at day 48 each weighed only $12 \mathrm{~g}$, and displayed both a fully developed penile clitoris and an absence of ovarian differentiation. The standard equation used by Lindeque and Skinner would have resulted in an estimated age of 40 days for these $12 \mathrm{~g}$ females (Table 1 ). Thus, there is no contradiction between our observations and those of Lindeque and Skinner in terms of the comparable sizes of fetuses, and the absolute fetal ages are not essential to the logic of the argument, although Lindeque and Skinner were studying older fetal material than their calculations indicated. It is entirely possible that the fetal ovary contributes androgens and facilitates genital growth during the later stages of gestation, but the undifferentiated state of the ovary observed in pregnancies $\mathrm{A}$ and $\mathrm{B}$ suggests that it is not likely to be functionally significant at the time the penile clitoris is formed.

Another apparent discrepancy between the present data and those reported by Lindeque and Skinner concerns the existence of gradients of testosterone concentrations between the umbilical artery and the umbilical vein. In a pair of fetuses estimated to be at day 80 of gestation (that is, $428 \mathrm{~g}$ fetuses), Lindeque and Skinner (1982) report 'high' concentrations of testosterone (1-4 $\left.\mathrm{ng} \mathrm{ml}^{-1}\right)$ in the umbilical artery and very low concentrations of testosterone $\left(<0.2 \mathrm{ng} \mathrm{m}^{-1}\right)$ in the umbilical vein. These data lead them to conclude that the fetus, not the placenta, is the source of testosterone. In this case, there is a direct contradiction between our conclusions and theirs. In the present study, umbilical vein values of $2.2 \mathrm{ng} \mathrm{ml}^{-1}$ of testosterone in a day 48 female fetus and $3-4 \mathrm{ng} \mathrm{ml}^{-1}$ of testosterone in a day 78 male fetus. The present values are in agreement with a previous report of substantial testosterone concentrations in cross-sections of the umbilical vein during late gestation (Glickman et al., 1992). Moreover, positive and substantial arterial-venous gradients of this steroid have never been observed in our studies (Glickman et al., 1992). Androgen is apparently cleared more slowly than oestrogen in the fetus. These discrepancies are difficult to interpret in the absence of information on the condition of their samples, but numerous measurements indicate that this finding, obtained from a single pair of fetuses, is anomalous.

Perhaps the most important point to emerge from the present study is that the capacity of the placenta to synthesize large amounts of testosterone relative to oestrogen from androstenedione is evident at early stages of gestation (on the basis of the metabolism of whole placentae, placental homogenates, and plasma steroid gradients in vivo) when the genitalia are already masculinized. While the undifferentiated state of the fetal ovary indicates that it is not a likely source of testosterone, the conspicuous enlargement of the adrenal with an extensive centrally located zone at day 33 raises the possibility that this tissue, in addition to the placenta, could serve as another early extragonadal source of steroid. Jaffe et al. (1981) have reported that the fetal zone of the rhesus monkey adrenal secretes dehydroepiandrosterone sulfate (DHAS) at stages of gestation generally comparable with the day 33 and 48 fetuses in the present study. Although this steroid would not normally be expected to activate the androgen receptor, the presence of appropriate enzymes in clitoral target tissues may result in conversion to testosterone or dihydrotestosterone. In addition, Avila et al. (1996) identified a single amino acid substitution in the steroid-binding domain of the spotted hyaena androgen receptor that is not present in the androgen receptor of the striped hyaena (a related species in which females show no signs of masculinization). The functional significance of this substitution is under study, but the authors have suggested that this mutation may increase the range of steroids that bind to the spotted hyaena androgen receptor.

Notwithstanding the evidence for a placental source of androgen for the fetus, the case for androgen induction of apparent masculine traits in females remains circumstantial. The possibility that the masculinized genitalia of the spotted hyaena reflect an androgen-independent mechanism, analogous to the autosomal mechanisms responsible for scrotal development in the tammar wallaby (Renfree and Short, 1988) has not been ruled out. In fact, attempts to demonstrate the effects of fetal androgens on clitoral and penile development through the use of anti-androgens and inhibitors of $5 a$-reductase activity during pregnancy have raised questions about their role in this species (Drea et al., 1998).

The authors thank the University of California Veterinary Staff, particularly D. Berger, D. DeNardo and P. Litwak, for carrying out the surgical procedures that were an essential component of the research reported in this paper. They are also grateful to D. Escontrias and M. Weldele for their assistance during surgery, and to $T$. Wu for contributing to the analysis of steroids. J. R. Brody assisted in the photographic presentation of histological sections. Finally, the authors owe particular debt to L. Frank, who initiated this line of research more than a decade ago, supervised the establishment of the spotted hyaena colony and has played a crucial role in the development of the Berkeley Hyena Project. This work was supported in part by Grant MH-39917 from the NIMH (to S. E. Glickman). 


\section{References}

Avila D, Wilson J, Glickman SE and McPhaul MJ (1996) Sequence analysis of the gene encoding the androgen receptor (AR) of the spotted hyena Program of the 10th International Congress of Endocrinology San Francisco, CA, p 188 Abstract

Conte FA, Grumbach MM, Ito Y, Fisher CR and Simpson ER (1994) A syndrome of female pseudohermaphrodism, hypergonadotropic hypogonadism, and multicystic ovaries associated with missense mutations in the gene encoding aromatase (P450arom) Journal of Clinical Endocrinology and Metabolism 78 $1287-1292$

Drea CM, Weldele M, Forger NG, Coscia EM, Frank LG, Licht P, and Glickman SE (1998) Androgens and masculinization of genitalia in the spotted hyaena (Crocuta crocuta). 2. Effects of prenatal anti-androgens Journal of Reproduction and Fertility (in press)

Ellinwood WE, Stanczyk FZ, Laxur JJ and Novy MJ (1989) Dynamics of steroid biosynthesis during the luteal-placental shift in rhesus monkeys Journal of Clinical Endocrinology and Metabolism 69 348-355

Ford JJ, Christenson K and Maurer RR (1980) Serum testosterone concentrations in embryonic and fetal pigs during sexual differentiation Biology of Reproduction 23 583-587

Frank LG (1986) Social organization of the spotted hyena, Crocuta crocuta. II. Dominance and reproduction Animal Behavior 34 1510-1527

Frank LG, Glickman SE and Licht $\mathbf{P}$ (1991) Fatal sibling aggression, precocial development, and androgens in neonatal spotted hyenas Science $\mathbf{2 5 2}$ 702-704

Frazer JFD and Huggett A StG (1974) Species variations in the foetal growth rates of eutherian mammals Journal of Zoology, London 174 481-509

Glickman SE, Frank LG, Pavgi S and Licht P (1992) Hormonal correlates of 'masculinization' in the female spotted hyaena (Crocuta crocuta). I. Infancy through sexual maturity Journal of Reproduction and Fertility 95 451-462

Goy RW and Resko JA (1972) Gonadal hormones and behavior of normal and pseudohermaphroditic monkeys Recent Progress in Hormone Research 28 $707-733$

Goy RW, Bercovitch FB and McBrair MC (1988) Behavioral masculinization is independent of genital masculinization in prenatally androgenized female rhesus monkeys Hormones and Behavior 22 552-571

Gross TS and Williams WF (1988) In vitro steroid synthesis by the placenta of cows in late gestation and at parturition Journal of Reproduction and Fertility 83 565-573

Harvey G, Pierrepoint CG, Anderson ABM, Turnbull AC and Griffiths K (1972) A time-based study of the in vitro metabolism of $\left[4-{ }^{14} \mathrm{C}\right]$-androstenedione and [1,2-3H2]epitestosterone by sheep placental tissue Biology of Reproduction 7 $15-24$

Huggett A St G and Widdas WF (1951) The relationship between mammalian foetal weight and conception age Journal of Physiology 114 306-317

Ito Y, Fisher CR, Conte FZ, Grumbach MM and Simpson ER (1993) Molecular basis of aromatase deficiency in an adult female with sexual infantilism and polycystic ovaries Proceedings of the National Academy of Sciences USA 90 $11673-11677$

Jaffe RB, Seron-Ferre M, Crickard K, Koritnik D, Mitchell BF and Huhtaniemi IT (1981) Regulation and function of the primate fetal adrenal gland Recent Progress in Hormone Research 37 41-103

Jost A, Vigier B, Prepin J and Perchellet JP (1973) Studies on sex differentiation in mammals Recent Progress in Hormone Research 29 I-35

Kruuk H (1972) The Spotted Hyena University of Chicago Press, Chicago

Licht P, Frank LG, Pavgi S, Yalicinkaya TM, Siiteri PK and Glickman SE (1992) Hormonal correlates of 'masculinization' in the female spotted hyaena (Crocuta crocuta). II. Maternal and fetal steroids Journal of Reproduction and Fertility 95 463-474

Lindeque M and Skinner JD (1982) Fetal androgens and sexual mimicry in spotted hyaenas (Crocuta crocuta) Journal of Reproduction and Fertility 65 $405-410$

Matthews LH (1939) Reproduction in the spotted hyaena, Crocuta crocuta (Erxleben) Philosophical Transactions of the Royal Society London, Series B 230 $1-84$

Miyairi S and Fishman J (1985) Radiometric analysis of oxidative reactions in aromatization by placental microsomes Joumal of Biologica! Chemistry $\mathbf{2 6 0}$ 320-325

Monaghan EP and Glickma SE (1992) Hormones and aggressive behavior. In Behavioral Endocrinology pp 261-285 Eds JB Becker, SM Breedlove and D Crews. MIT Press, Cambridge, MA

Neaves WB, Griffin JE and Wilson JD (1980) Sexual dimorphism of the phallus in spotted hyaena (Crocuta crocuta) Journal Reproduction and Fertility 59 509-513

Racey PA and Skinner JD (1979) Endocrine aspects of sexual mimicry in spotted hyaenas (Crocuta crocuta) Journal of Zoology, London 187 315-326

Renfree MB and Short RV (1988) Sex determination in marsupials: evidence for a marsupial-eutherian dichotomy Philosophical Transactions of the Royal Society, London Series B 322 41-53

Shozu M, Akasofu K, Harada T and Kubota Y (1991) A new cause of female pseudohermaphroditism: placental aromatase deficiency Journal of Clinical Endocrinology and Metabolism 72 560-566

Sinclair AH, Berta P, Palmer MS, Hawkins JR, Griffiths BL, Smith MJ, Foster JW, Frischauf AM, Lovell-Badge R and Goodfellow PN (1990) A gene from the human sex-determining region encodes a protein with homology to a conserved DNA-binding motif Nature 346 240-244

Watson $M$ (1877) On the female generative organs of Hyaena crocuta. Proceedings Zoological Society 24 369-378

Wilson JD, George FW and Griffin JE (1981) The hormonal control of sexual development Science 211 1278-1284

Wilson JD, Griffin JE, George FW and Leshin M (1983) The endocrine control of male phenotypic development Australia journal of Biological Science 36 $101-128$

Yalcinkaya TM, Siiteri PK, Vigne JL, Licht P, Pavgi S and Glickman SE (1993) A mechanism for virilization of female spotted hyenas in utero. Science $\mathbf{2 6 0}$ 1929-1931 